\title{
Transport Factors Affecting the Outcome of Referred Neonates Admitted in A Tertiary Care Hospital
}

\author{
MADHABI BAIDYA ${ }^{1}$, MAHFUZA SHIRIN ${ }^{2}$, LITON CHANDRASAHA ${ }^{3}$
}

\begin{abstract}
Background: Adequate neonatal transport is a key component of care of the sick newborns who require referral to tertiary care center. Poor transportation is one of the iatrogenic factors associated with greater neonatal mortality. Neonatal transport is the greatest challenge faced today in our country. The purpose of this study was to find out characteristics of transport of referred neonates and to idention the factors that contribute to mortality.
\end{abstract}

\begin{abstract}
Methodology: This cross sectional study was conducted in Dhaka Shishu (Children) Hospital from June 2013 to November 2013. Both term and preterm neonates who were referred within first seven days of life were included and those with gross congenital abnormalities and left against medical advice were excluded from the study. After enrollment, data were collected using a structured questionnaire including birth details, interventions before transportation, reasons for referral, and details of transportation. Outcome \& duration of hospital stay were also recorded. Neonates who were expired considered as group I and who were survived considered as group II. The study variables were analyzed for their association with immediate outcome by applying chi square test and t test. $P$ value $<0.05$ was considered significant.
\end{abstract}

Results: This study found that out of 332 neonates 181 were expired with $54.5 \%$ mortality rate. One eighty one neonates who were expired, considered as group I and one fifty one neonate were survived, considered as group II. The mortality was significantly high in male neonates [RR $0.80(0.66-0.97)]$ and neonates those delivered at home $[R R$ 1.34(1.10-1.64)] ( $p<0.05)$. Perinatal asphyxia, pre-term low birth weight, neonatal sepsis were the main causes of referral.

It was found that transportation without any referral note [RR 1.40 (1.14-1.71)], no advice regarding maintenance of airway[RR 1.50(1.17-1.92)] and keeping warm [RR 1.51(1.17-1.950], resuscitation on admission [RR 1.63(1.23-2.17)] and transportation required $>$ 3hours [RR 1.36(1.09-1.69)] were associated with significantly higher mortality among referred transported neonates $(p<0.05)$.

Conclusions: This study found that male neonates, home delivery, transportation without any referral note, no advice regarding maintenance of airway and keeping warm, resuscitation needed on admission and prolonged transportation time were significantly associated with mortality of referred transported neonates.

Key words: Neonatal transport, mortality, referred newborns.

1. Resident Medical Officer, Dhaka Shishu (Children) Hospital.

2. Associate Professor, Department of Neonatology, Bangladesh Institute of Child Health, Dhaka Shishu (Children) Hospital.

3. Assistant Professor, Department of Neonatology, Bangladesh Institute of Child Health, Dhaka Shishu (Children) Hospital.

Correspondence to: Dr. Madhabi Baidya, Resident Medical Officer, Dhaka Shishu (Children) Hospital. Cell: 01817712445, Email:madhabibaidya018@gmail.com

Received: 10 June 2017

Accepted: 14 November 2017

\section{Introduction}

Every year all over the world, 130 million babies are born and among them about 4 million babies die during neonatal period. ${ }^{1}$ Neonatal mortality and disease pattern is a sensitive indicator of availability, utilization and effectiveness of mother and child health services in the Community. ${ }^{2}$ Birth asphyxia $(23 \%)$, pretermlow birth weight (45\%), severe infection (20\%), diarrhea 
$1 \%$, and others ( $4 \%$ ) were the major direct causes of death. ${ }^{3}$ Since causes of neonatal death vary by country with the availability and quality of health care, understanding neonatal mortality in relation to these factors is crucial. Many of these are easy to manage and significantly decrease in neonatal mortality can be anticipated with regionalization of perinatal care, where many sick newborn can be provided with better care and outcome if they are timely transported in stable condition. ${ }^{4}$

Adequate neonatal transport is a key component of care of the sick newborns who require referral to tertiary centers that provide higher levels of care. When a newborn is referred, transport may interfere with several aspect of his or her homeostasis such as thermoregulation, metabolic stability, fluid and electrolyte balance and cardio-respiratory status. This interference may cause clinical deterioration especially when the quality and continuity of monitoring and/or treatment is not ensured as during hospitalization. Instability or complication arising during transport may result in greater morbidity and mortality in this vulnerable newborn infants. ${ }^{5}$

Most of the neonatal transports are self-transport without any pre-treatment stabilization or care during transport. Many of these newborns thus transported are cold, blue and hypoglycemic and $75 \%$ of these babies transferred this way have serious clinical implications. ${ }^{6}$

The present study was done to findout characteristics of transport of referred neonates and to identify the factors that contribute to mortality.

\section{Methodology}

This is a cross sectional study, conducted in Dhaka Shishu (Children) Hospital from June 2013 to November 2013. Both term and preterm neonates who referred within first seven days of life were included in this study. Neonates with gross congenital abnormalities and left against medical advice were excluded. After enrollment birth details including weight, gestation, place of birth, transport details such as mode of transport, time taken to reach the hospital, condition of patient prior to transport, whether accompanied by trained personnel or not, and need for any resuscitation was recorded. Gestational age was calculated as total duration of pregnancy in weeks from the first day of the last menstrual period to birth of the baby and valiaated by doing New Ballard Score. Data was collected by using a structured questionnaire.
Ethical clearance was obtained from Ethical Review Committee of Bangladesh Institute of Child Health, Dhaka Shishu (Children) Hospital and informed written consent was taken from parents.

Statistical analysis was carried out by using the Statistical Package for Social Sciences version 16.0 for Windows (SPSS Inc., Chicago, Illinois, USA). The study variables were analyzed for their association with immediate outcome by applying chi square test and $t$ test. $P$ value $<0.05$ was considered significant.

\section{Results}

A total of 385 neonates were screened among them 53 neonates were excluded and finally data of 332 neonates were analyzed. Total 181 neonates were expired with $54.5 \%$ mortality rate. One eighty one neonates who were expired, considered as group I and one fifty one neonate were survived, considered as group II.

The mortality was significantly high in male neonates [RR $0.80(0.66-0.97)]$ and neonates those delivered at home $[R R$ 1.34(1.10-1.64)] $(p<0.05)($ Table-l). The mean admission weight was $2.2 \pm 0.6 \mathrm{Kg}$ and $2.3 \pm 0.6 \mathrm{Kg}$. Term neonates were more than preterm neonates in group I and group II respectively but there was no significant difference in mortality in between them (Table I). Common indications for referral were Perinatal asphyxia followed by neonatal sepsis, preterm low birth weight (Figure 1). Most 134 (74.0\%) of the patients came from Dhaka city and its surrounding areas in group I and $112(74.2 \%)$ in group II.

Most of the neonates were transported by Ambulances and rest was by cars, taxis or auto rickshaws. Ambulance was used in $71.3 \%$ in group I and $68.2 \%$ in group II (Table II). Most of the ambulances were equipped with one oxygen cylinder but there were no equipment for resuscitation or warming. These ambulances were manned by a driver alone.

It was found that most of the neonates $(173 / 181,147$ / 151) were accompanied by relatives in group I and group II respectively. It was found that transportation without any referral note [RR 1.40 (1.14- 1.71)], no advice regarding maintenance of airway [RR 1.50(1.171.92)] and keeping warm [RR 1.51(1.17-1.950], resuscitation on admission [RR 1.63(1.23-2.17)] and transportation time $>3$ hours [RR 1.36(1.09-1.69)] were significantly associated units higher mortality of referred transported neonates $(p<0.05)$ (Table II). 
Table I

General characteristics of referred neonates on arrival at hospital $(n=332)$

\begin{tabular}{|c|c|c|c|c|c|}
\hline General characteristics & $\begin{array}{c}\text { Group I } \\
\mathrm{n}(\%)\end{array}$ & $\begin{array}{c}\text { Group II } \\
\mathrm{n}(\%)\end{array}$ & $\mathrm{RR}$ & $95 \% \mathrm{Cl}$ & Pvalue \\
\hline \multicolumn{6}{|l|}{ Gestation } \\
\hline Term & $119(65.7 \%)$ & $100(66.2 \%)$ & 1.01 & $(0.82-1.24)$ & $0.926^{*}$ \\
\hline Pre-term & $62(34.3 \%)$ & $51(33.8 \%)$ & & & \\
\hline \multicolumn{6}{|l|}{ Gender } \\
\hline Male & $89(49.2 \%)$ & $56(37.1 \%)$ & 0.80 & $(0.66-0.97)$ & $0.027^{*}$ \\
\hline Female & $92(50.8 \%)$ & $95(62.9 \%)$ & & & \\
\hline \multicolumn{6}{|l|}{ Residence } \\
\hline Urban & $80(44.2 \%)$ & $73(48.3 \%)$ & 0.93 & $(0.76-1.13)$ & $0.450^{*}$ \\
\hline Rural & $101(55.8 \%)$ & $78(51.7 \%)$ & & & \\
\hline \multicolumn{6}{|l|}{ Place of delivery } \\
\hline Home & $100(55.2 \%)$ & $59(39.1 \%)$ & 1.34 & $(1.10-1.64)$ & $0.003^{*}$ \\
\hline Hospital/clinic & $81(44.8 \%)$ & $92(60.9 \%)$ & & & \\
\hline \multicolumn{6}{|l|}{ Socio economic status } \\
\hline Poor /Below avg. & $100(55.3 \%)$ & $73(48.3 \%)$ & 1.13 & $(0.93-1.38)$ & $0.209^{*}$ \\
\hline Average & $81(44.7 \%)$ & $78(51.7 \%)$ & & & \\
\hline \multicolumn{6}{|l|}{ Admission weight } \\
\hline$<1500 \mathrm{~g}$ & $30(16.6 \%)$ & $18(11.9 \%)$ & & & \\
\hline $1500-2500 \mathrm{~g}$ & $111(61.3 \%)$ & $93(61.7 \%)$ & & & \\
\hline $2500 \mathrm{~g}$ & $40(22.1 \%)$ & $40(26.4 \%)$ & & & \\
\hline Mean $\pm S D$ & $2.2 \pm 0.6$ & $2.3 \pm 0.6$ & $0.131 \#$ & & \\
\hline
\end{tabular}

$\mathrm{RR}=$ relative risk; $\mathrm{Cl}=$ confidence interval; ${ }^{*}=\mathrm{\partial}^{2}$ test; $\#=\mathrm{t}$ test.

Table-II

Transport characteristics of referred neonates $(n=332)$

\begin{tabular}{lcccc}
\hline Transport characteristics & $\begin{array}{c}\text { Group I } \\
\mathrm{n} \%\end{array}$ & $\begin{array}{c}\text { Group II } \\
\mathrm{n} \%\end{array}$ & RR 95\% Cl & Pvalue $^{*}$ \\
\hline No pre-referral treatment & $83(45.9 \%)$ & $54(35.8 \%)$ & $0.83(0.68-1.01)$ & 0.062 \\
Transportation without referral note & $106(58.6 \%$ & $61(40.4 \%)$ & $1.40(1.14-1.71)$ & 0.001 \\
No advice regarding maintenance & $136(75.1 \%)$ & $86(57.0 \%)$ & $1.50(1.17-1.92)$ & 0.001 \\
of airway & & & & \\
No advice regarding feeding & $160(88.4 \%)$ & $125(82.8 \%)$ & $1.26(0.90-1.76)$ & 0.143 \\
No advice regarding keeping warm & $139(76.8 \%)$ & $89(58.9 \%)$ & $1.51(1.17-1.95)$ & 0.001 \\
Accompanied by relatives & $173(95.6 \%)$ & $147(97.4 \%)$ & $0.81(0.54-1.23)$ & 0.389 \\
Time took to reach DSH $>3$ hours & $120(66.2 \%)$ & $72(47.6 \%)$ & $1.36(1.09-1.69)$ & 0.001 \\
Resuscitation on admission & $147(81.2 \%)$ & $94(62.3 \%)$ & $1.63(1.23-2.17)$ & 0.001 \\
\hline
\end{tabular}

${ }^{*}=\partial^{2}$ test 


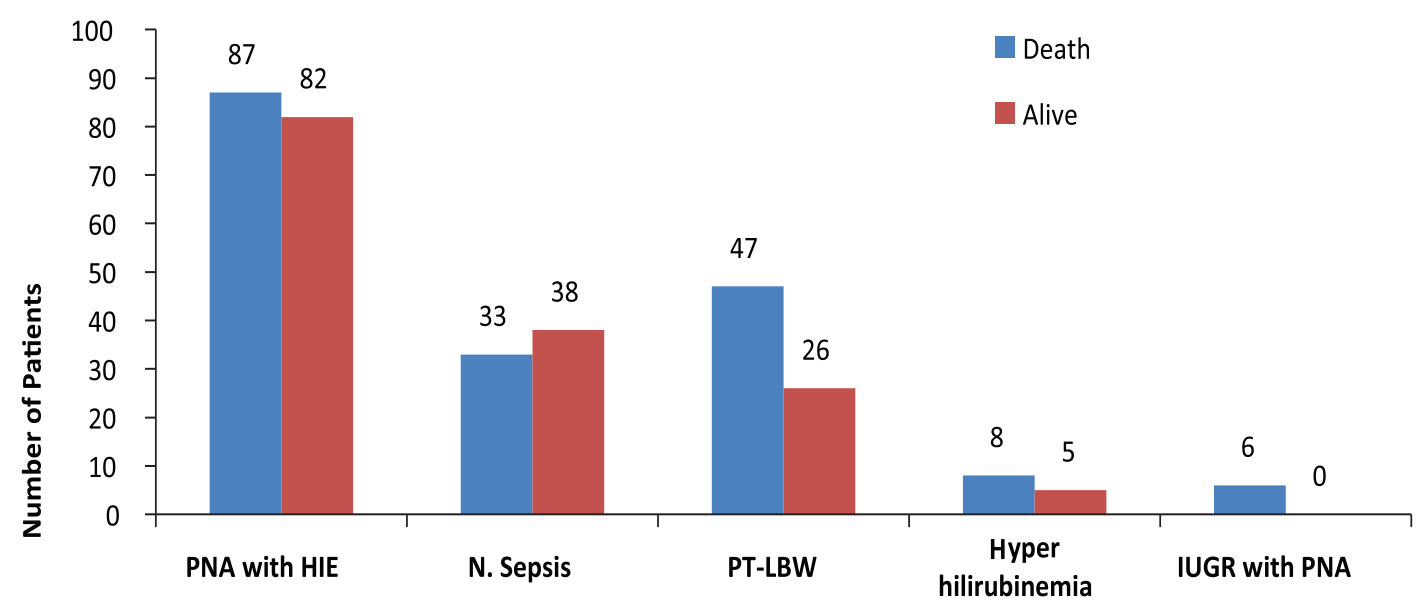

Fig.-1: Showing cause of referral

\section{Discussion}

This cross-sectional study was carriedout with an aim to identify the cause of referral, identify the duration to reach at hospital, mode of transport, and to find out their association with neonatal mortality.

Total 332 neonates were enrolled, among them 181 expired with $54.5 \%$ mortality rate. Narang et $\mathrm{al}^{7}$ reported proportion of children who expired was $46.3 \%$, which was nearer to this study findings. But study conducted by Buch et al ${ }^{5}$ revealed overall mortality of referred neonates was $32.2 \%$ and Shegal et al ${ }^{8}$ demonstrated that only $19.5 \%$ referred newborns were expired. Both of these findings were less than that of our findings.

In this present study, it was observed that male neonates and home delivery was significantly more in group I, but gestational age, weight, residence and socioeconomic status were similar in two groups. Rakholia et $\mathrm{al}^{6}$, found that more male babies (63.25\%), and $53.54 \%$ were out born and $46.46 \%$ inborn which was similar to our findings. Narang et al ${ }^{7}$ found only $24.3 \%$ neonates were born by home delivery, which was not like of this study.

Prematurity, asphyxia and sepsis are the most common causes of neonatal mortality in developing countries $^{9}$. Many of these are easy to manage and significant decrease in neonatal mortality can be anticipated with regionalization of perinatal care, where many sick newborns can be provided with better care and outcome if they are timely transported in stable condition. Individual morbidity and cause for mortality have not changed in developing countries though many of them can be managed properly. Perinatal asphyxia, respiratory distress syndrome (RDS), Sepsis and Meconium aspiration syndrome were most common morbidity among multiple co-morbidities. Incidence of sepsis and RDS among preterm and LBW babies are the major causes for immediate adverse outcome in developing countries of Asia and Africa 7,9

In this present study it was observed that neonates were referred due to PNA, Neonatal sepsis, PTLBW, neonatal hyperbilirubinemia, and IUGR with PNA. Mortality was significantly $(p=.031)$ higher among the referred neonates with PNA, PT-LBW and IUGR with PNA. These observations were similar to those of Rakholia et $\mathrm{al}^{6}{ }^{6}$ Narang et $\mathrm{al}^{7}$ and Kazemian et $\mathrm{al}^{10}$.

Regarding relationship between mortality and duration of transport time Narang et al ${ }^{7}$ mentioned in their study that mortality was inversely related to time taken to reach hospital, transportation time $>1$ hour (OR: 5.58 [95\%] Cl: 1.41-22.01) $(P<0.05)$ to be significantly associated with mortality of transported neonates. Mori et $\mathrm{al}^{11}$ found that neonates with long duration of transport (undefined) had $79 \%$ higher odds of death than those with short duration $(95 \%$ confidence intervals [Cl]: $1.38-8.42$ ) after adjusting for the confounding effects of admission weight, hypothermia, hypoglycemia, delayed capillary filling time, cyanosis and prematurity. Another cross-sectional study conducted in an urban area in India reported that there was strong evidence that those transported for $>90$ min had more than twice the rate of neonatal death (RR 1.81, 95\%Cl: $1.07-3.06$ ) and some evidence that those transported for between 60 and $89 \mathrm{~min}$ had an $80 \%$ higher rate of neonatal death both compared 
with those transported for between 30 and $59 \mathrm{~min}$, after adjusting for the confounding effects ${ }^{13}$.These were the evidence of an association between duration of transport and increased neonatal mortality. In this study it was observed that there was significant difference of time took $>3$ hours to reach the hospital (DSH) (RR: 1.36 [95\% Cl]: $(1.09-1.69)(p<0.05)$. We also observed that majority of neonates were referred from Dhaka district ( 74\%).

All these findings were similar to our findings. We also observed that majority of neonates were referred from Dhaka district ( 74\%).

We found that to transport the referred neonates ambulance were used mostly, $71.3 \%$ in group I and $68.2 \%$ in group II, the difference was not statistically significant $(p>0.05)$. Similarly Kazemian et al. ${ }^{10}$ showed that $57.9 \%$ cases the transport vehicle was a hospital ambulance while in rest of the cases, it was a private ambulance. None of the ambulances had optimal equipment. Also Dalal et al ${ }^{12}$ reported that about half $(47.3 \%)$ were transported in ambulance, but rest were transported in auto rickshaw $(33.0 \%)$, in open vehicle (18.3\%) and in bus (1.4\%). But Narang et $\mathrm{al}^{7}$ reported that most of the neonates were transported by either a private vehicles $41.0 \%$ or by a public transport (bus/train) 29.3\%. They found ambulance was used for transporting only in $29.6 \%$ neonates. Most of these ambulances were equipped with one oxygen cylinder, but there were no equipment for resuscitation or warming. But Shegal et $\mathrm{al}^{8}$ observed that common mode of transports was taxi $47 \%$, bus $16 \%$, auto $16 \%$ and $2.5 \%$ of neonates were transported by ambulance. It was found by Mori et $\mathrm{al}^{11}$ that infants born at home $(45 \%)$ were transported from home and means of transport varied from bicyclerickshaws to ground ambulances.

In this study, most of the newborns were referred without proper pre-referral stabilization (RR: 0.83; 95\%[Cl]: 0.68-1.01) ( $p>0.05)$, documentation or communication (RR: 1.40; 95\% [Cl]: 1.14$1.71)(p<0.05)$, and skilled attendant accompanying newborn(RR:0.81; 95\%[Cl]: 0.54-1.23) ( $p>0.05)$. Also there was no advice regarding maintain airway (RR:1.50; 95\%[Cl]: 1.17-1.92) $(p<0.05)$, keeping warm (RR:1.51; 95\%[Cl]: 1.17-1.95) $(p<0.05)$ and feeding (RR:1.26; 95\%[Cl]: 0.90-1.76) $(p>0.05)$ during transport. However there is improvement in transport system compared to earlier studies. In a study by Sehgal et al ${ }^{8}$ none of referrals had been pre-informed and none of referrals were accompanying by trained health personnel and none of babies had been fed during transport. In another study Dalal et al. ${ }^{12}$ reported that pre referral stabilization was found $46.4 \%$ survived and $54.7 \%$ expired group. Narang et $\mathrm{al}^{7}$ found that there was lack of accompanying clinical note in twothird of neonates $66.6 \%$. Before the transport of neonates, prior information was sent to referral center in only $7.6 \%$ neonates; and prior counseling of parents (regarding the need of transport) were carried out in $21.3 \%$ neonates and the baby was accompanied by health personnel only in $15.6 \%$ neonates. Kazemian et $\mathrm{al}^{10}$ showed that $84.21 \%$ the father accompanied the infant, while in $15.79 \%$ another relative accompanied the infant. Health care professionals also often accompanied the patient; in $78.9 \%$ a nurse and in $21.1 \%$ interns accompanied the patient. Out of these 19 health care personnel who accompanied the patients, $42.1 \%$ had participated in neonatal resuscitation workshops. None of the transported infants was intubated but all of them had intravenous lines.

\section{Conclusion}

This study found that factors those were associated with higher mortality of transported referred neonates were male neonates, home delivery, transported without any referral note, no advice regarding maintain airway and regarding keeping warm, resuscitation needed on admission, and prolonged transportation time.

\section{Limitations of the study}

1. The study population was selected from one selected hospital in Dhaka city, so that the results of the study may not reflect the exact picture of the country.

2. The present study was conducted at a very short period of time.

\section{References}

1. Singh M, Parsuraman S. Neonatal Mortality in South Asia: Treands, Differentials and Determinants. Indian Pediatr 2013; 1(4): 1-24.

2. Bangladesh demographic and health survey. 2014; 1-56.

3. Hussain S. Neonatal morbidity and mortality pattern in a tertiary care neonatal unit of a teaching hospital. Ann Pak Inst Med Sci 2014; 10(1): 7-11. 
4. Rubayet S,Shahidullah M, Hossain A, Corbett E, Moran A, Mannan I. Newborn survival in Bangladesh : A decade of change and future implications. Health Policy and Planning 2012; 27(Suppl 3): iii40-iii56.

5. Buch P M, Makwana A M, Chudasama R K, Doshi SK. Status of newborn transport in periphery and risk factors of neonatal mortality among referred newborns. JPBMS 2012; 16(9): 1-6.

6. Rakholia R, Rawat V, Bano M, Singh G. Neonatal morbidity and mortality of sick newborns admitted in a teaching hospital of Uttarakhand.CHRISMED J Health Res 2014; 1(4): 228-34.

7. Narang N, Kaushik JS, Sharma KA, Faridi MMA. Predictors of mortality among the neonates transported to referral centre Delhi, India.Indian J Public Health 2013; 57: 100-104.

8. Shegal A, Roy MS, Dubey NK, Jyothi MC. Factor contributing to outcome in newborns delivered out of hospital and referred to a teaching institutions. Indian Pediatr 2001; 38: 1289-94.

9. Kumar P, Kumar C, Venkatlakshmi A. Long distance neonatal transport-the need of hour. Indian Pediatr 2008; 45: 920-22.

10. Kazemian M, Fakhraee SH, Zonouzi F. Neonatal transport in Tehran: Acause of much concern.Arch Iranian Med 2004; 7(4): 256-59.

11. Mori R, Fujimura M, Shiraishi J, Evans B, Cornett $M$, Nequshi $\mathrm{H}$, et al. Duration of inter-facility neonatal transport and neonatal mortality: Systematic review and cohort study. Pediatr Int 2007; 49(4): 452-58.

12. Dalal E, Vishal G, Solanki D.Study on Neonatal Transport at tertiary care Centre.IJSR 2013; 2(12): 289-92.

13. Rao SK, Bajaj N, Rawat A. Pre-transport factors and transport quality affecting the neonatal outcome. JEMDS 2015; 4(12): 1991-95. 